\title{
ELS ORIGENS DE LA SOCIOLOGIA A CATALUNYA I LA FIGURA DE SANTIAGO VALENTI I CAMP
}

\author{
Teresa Torns \\ (Facultat de Ciències Politiques i Sociologia \\ de la Universitat Autònoma de Barcelona)
}

La premissa que hi ha implícita en l'argumentació que segueix és que del coneixement de la història sempre se'n pot derivar un millor coneixement del present. D'altra banda sembla prou consensuable definir la sociologia com un dels possibles coneixements del present. Per tant, sembla també prou legítim tractar d'esbrinar la situació actual de la sociologia a Catalunya a través de la història dels seus orígens.

L'estudi dels orígens és certament un tema poc tractat entre els sociòlegs d'aquest país, siguin o no siguin afeccionats a la història. El curt recorregut bibliogràfic que qualsevol persona intetessada pot realitzar sobre la qüestió així ho palesa: I'Ictineu, Diccionari de les Ciències de la Societat als Paisos Catalans; alguns estudis sobre l'obra de Jaume Balmes, J. M. Llovera i el bisbe Torras i Bages; unes breus referències, en l'apartat sobre Espanya, escrites per E. Boix Selva per a l'Enciclopedia Universal Ilustrada, d'Espasa-Calpe, i un petit article sobre l'ensenyament de les ciències socials a la primera Universitat Autònoma de Barcelona en temps de la Segona República. ${ }^{1}$

1. Vegeu en l'Ictineu. Diccionari... l'entrada «Sociologia» firmada conjuntament per Salvador Salcedo, Joan Estruch i Salvador Giner. Vegeu també l'apartat «Treball» signat per Jordi Estivill. Sobre J. Balmes, veget entre altres estudis, el número monogràfic «Balmes y lo social» de la Revista Internacional de Sociología, núm. 22-23, que es va publicar l'any 1948 amb motis del primer centenari de la seva mort; l'estudi de H. Auhofer, La Sociología de J. Balmes, Madrid, 1959 i també l'article de M. Fraga Iribarne, «Balmes, fundador de la sociología positiva en España», Vic, 1955. 
Les possibles explicacions del perquè d'aquesta migradesa, actualment desconegudes, podtien segurament servir d'objecte d'estudi per a recerques futures. I ben certament, en aquestes tecerques, si mai es duien a terme, caldria considerar-hi factors com les dificultats i la manca de consolidació que Ia sociologia ha hagut d'afrontar a Catalunya des dels seus orígens. Per no parlar de com aquests inconvenients segurament han incidit en els professionals i en els seus estudis, de tal manera, que els esforços realitzats per sobreviure no els han permès de mirar enrera i dirigir les seves reflexions $i$ anàlisis vers els qui foren els seus avantpassats $i$ allò que van fer.

En qualsevol cas, i mentre no es duen a terme les dites recerques, una manera de cercar més informació sobre els orígens de la sociologia a Catalunya és ampliar el context geogràfic a l'Estat espanyol. I, efectivament, en aquest àmbit es poden trobar més estudis $i$ interessos dedicats a esbrinar quins han estat els inicis d'aquesta ciència social. La literatura generada a l'entorn de la sociologia a Espanya presenta lògicament molt diversos resultats donada la pluralitat d'enfocaments i perspectives corresponents als diferents autors que l'han propiciada. ${ }^{3}$ Però si malgrat tot es tenen en compte només els acords, val a dir que un dels més consensuats és el que fa referència als corrents de pensament que van possibilitar l'aparició d'aquesta ciència arret de l'Estat. A saber, el positivisme, el catolicisme social, el krausisme i, encara que en menor mesura, el regeneracionisme.

Traslladar mitnèticament els models d'explicació que han servit per analitzar un determinat fenomen o una determinada parcella de la realitat no acostuma a donar bons fruits en el camp de les ciències socials. $O$ en

Sobre J. M. Llovera, vegeu especialment el pròleg d'E. Boix i Selva a la vuitena edicib del seu Tratado de Sociología Cristiana, Barcelona, 1953. Sobre Torras i Bages, vegeu de Martí Brugarola, Sociologia cristiana del Dr. Torras y Bages (en el centenario de su nacimiento), Batcelona, 1947. L'article d'E. Boix Selva està publicat al Suplemento 1957-58 de t'Enciclopedia Universal Ilustrada d'Espasa Calpe, Madrid, 1961, sota l'encapçalament «Sociologia» i existeix també com 'a separata amb el títol Tendencias actuales de la Sociología. Per últim l'article de F. Mercadé es titula aLes ciències socials a la Universitat Aurònoma de Barcelona» a Papers, núm. 6, Barcelona, 1977.

2. Només cal recordar que la primera facultat de Sociologia a Catalunya té com a data de creació el 1986. I que tot $\mathrm{i}$ que això no ha impedit l'existència de nom. brosos sociolegs, que han hagut de formar-se fora o/i a precati, ni l'existencia de diversos intents de crear escoles de Sociologia, és prou reconeguda la necessitat de consolidar acadèmicament una disciplina per tal de poder-la institucionalitzar i legitimar.

3. Vegeu un resum de la bibliografia existent sobre el tema a la meva tesi doctoral, Teresa Torns, Sobre los origenes de la Sociología en Catalunya. Las aportaciones de los anarquistas (1864-1910), de la qual també s'ha extret tota la informació d'a. quest atticle. 
aquest cas, i dit d'una altra manera, tertitorialitzar la informació pot conduir a l'enriquiment de les dades que han estat tractades massa globalment. I aquest és un dels casos on es produeix aquest fet. És a dir, si d'una banda, donada la migradesa d'estudis sobre els orígens de la sociologia a Catalunya, l'ampliació del context sembla ineludible, un cop analitzada la presència dels citats cortents de pensament en l'àmbit català, el resultat obtingut posa de manifest els inconvenients de l'esmentada globalització. I per tant, com a resum abreujat d'aquesta anàlisi podria dir-se que a Catalunya, per exemple, no hi va haver krausisme, que és el corrent que protagonitza el sorgiment de la sociologie a Espanya. Aquest paper segons tots els indicis correspondria, en aquest indret, al catolicisme social. Sí que hi va haver en canvi positivisme, perquè, de fet, tant Pere Estasén com Pompeu Gener eren catalans, i pel que fa al regeneracionisme, només pot parlar-se de la figura de Santiago Valentí i Camp, tot i que pot resultar una mica agosarat quali. ficar-lo com a regeneracionista.

No són aquestes evidentment les úniques diferències sorgides de la co. mentada territotialització, " però sí les més interessants pel que fa a la qües* tió que aquí es vol tractar: la figura de Santiago Valentí i Camp i la seva tasca com a pioner de la sociologia a Cataltunya. Generalment teconeixem el nom i l'obra de Manuel Sales i Ferré ${ }^{5}$ com el primer cas de sociòleg català i cal dir que el nom nou, reivindicat aquí, no es suggereix pas amb la intenció de dur a terme cap canvi de jeratquia entre els ancestres. Tanmateix, la intenció que mou aquesta reivindicació és tan sols la de posat de manifest l'interès d'una figura que fins al moment ha restat oculta en la història de les ciències socials catalanes. Característica que, per altra banda, tal com ja $z$ 'hem dit alguna cosa abans, comparteix amb gairebé la testa de la història dels orígens del coneixement sociològic català, petò de la qual, en aquesta ocasió, es vol fer especial esment, perquè molt probablement sigui producte de dos factors. El primer, que Santiago Valentí i Camp no va desenvolupar la seva obra a la Universitat i el segon, que la defensa de la seva ideologia el portà a militar activament en la política del moment. I no

4. Una de les diferències primordials és la telativa al paper jugat en aquests origens pels anarquistes en el context català, tema principal de la tesi doctoral abans esmentada.

5. Vegeu l'estudi de M. Núñez Encabo, Manual Sales y Ferré: Los origenes de La Sociologís en España, Madrid, $1976 \mathrm{i}$ el de R. Jerez Mir, La introducción de la So. ciologia en España. Manuel Sales y Ferré: Uno experiencia truncado, Madrid, 1980.

6. Valentí i Camp fou diputat provincial per Batcelona com a membre del Partit Radical el 1911. Formà part del Bloc Republicà Autonomista amb Francesc Layret i Marcellí Domingo i posteriorment fou membre del. Partit Catala Republicà. En el moment de la seva mort, el 1934, era president de l'Ateneo Socialista. 
«Papers»: Revista de Sociologia

calen gaites recerques per evidenciar que el fet d'actuar fora de la vida acadèmica i lluny dels qui governen ha estat i és un camí vers la foscor.

\section{LA FIGURA DE SANTIAGO VALENTI I CAMP}

No seria, però, prou correcte d'iniciar aquí l'explicació sobre la figura de Santiago Valentí i Camp tot dient que dins de l'àmbit de la sociologia espanyola no se n'ha parlat mai i que per tant l'esmentada foscor ba estat absoluta. Amando de Miguel, a la seva prolífica carrera com a publicista, el cita concretament a Sociología o subversión. ${ }^{2}$ En aquest text, l'autor pretén entre d'altres coses completar la informació sobre els orígens de la sociologia espanyola, que fins al moment tenien com a punt de referència obligada un article d'Enxique Gónez Arboleya publicat a la Revista de Estudios Políticos. ${ }^{8}$ De Miguel en el capítol titulat «Las tribulaciones de una nueva ciencia, o la historia de una frustración destaca el nom de San. tiago Valentí i Camp i el del catedràtic de Dret Penal Quintiliano Saldaña com dos noms oblidats per Gómez Arboleya.

També José Luis Iturxate ha citat aquest sociòleg català. Ho fa a l'apèndix que va escriure pel diccionari La Sociologí,. En concret escriu una nota breu, on comenta també la figura del pare d'aquest personatge, Ignasi Valentí Vivó. Sobre l'esmentat Valentí Vivó cal precisar també que fou un metge higienista continuador de la tradició que a Catalunya iniciaren professionals de la medicina com el doctor Felip Monlau o el doctor Salarich. Tradició que, en cetta manera, va propiciar la realització dels primers estudis sobre les condicions de vida dels obrers catalans. ${ }^{10}$ Per últim, R. Jetez Mir en la seva obra ${ }^{13}$ destaca breument el paper que va tenir Valentí $i$ Camp en els otígens de la sociologia espanyola. Es pot dir per tant que és un personatge relativament desconegut dins la literatura sociològica especian litzada.

7. A. de Miguel, Sociología o subversión, Esplugues de Llobregat, 1972.

8. E. Gómez Arboleya, «Sociología en España» a Revista de Estudios Politicos, núm. 98, Madrid, 1958.

9. J. L. Iturtate, Sociologío en España. Notas paro su bistoria en el diccionati de J. Cazeneuve, D. Victorofe, La Sociología, Bilbao, 1975.

10. En aquests primers moments de sociografia sobre la classe obrera catalana, cal incloure també Ia Monografía estadística de la clase obrere en Barcelona que Ildefons Cerdà va publicar com anpex de la seva Teoría general de lo urbanización (1867).

11. Vegeu nota núm, 5 . 
Unes primeres dades sobre la biografia de Valentí i Camp poden ampliar-se en el llibre d'E. Navarro, Historia crítica de los bombres del republicanismo catalán en la última década (1905-1914). ${ }^{22}$ Segons tota la informació recopilada, pot aventurar-se la idea que l'obra sociològica de Valentí i Camp va sorgir en un context $i$ en unes circumstàncies històriques que no la van fer viable en el seu temps $i$ fins $i$ tot que var impedir la seva posterior repercussió històrica. Encara que sembla prou evident que, donada la seva posició social i les seves activitats polítiques $i$ intellectuals, sempre va tomandre prop dels nuclis iniciadors de la consolidació acadènica i no acadèmica de la sociologia catalana. Petò aquesta proximitat va estar plena de matisos. Valentí no formà part del corrent que a Catalunya impulsà majoritàriament la nova ciència de la societat, l'anomenat catolicisme social. A més, tot i ser membre de la classe burgesa, sempre mantingué actituds més properes a una esquerra moderada $i$ per tant defensà idees més progressives en relació a la nova ciència. No cal dir, doncs, que Iluny de les visions d'un Torras i Bages o d'un Ignacio M. de Ferrán, la seva cultura sociològica, no adquirida a la Universitat espanyola de l'època, el convertiren en un rara avis.

Podríem dir que Valentí fou en certa manera un regeneracionista en un context social i polític poc amant del regeneracionisme. L'ideari i l'actuació de la gran burgesia catalana emmirallada i enriquida durant la febre de l'or $i$ els grans negocis de la Primera Gran Guerra quedaven força allunyats dels laments d'aquest intellectual, per la crisi de valors que patia Espanya. Fins i tot el lleu matís krausista que algú ha volgut veure a la seva obra no podia tenir tessò en una sociologia que a la Catalunya de l'època preferia seguir el mestratge de Lleó XIII. ${ }^{13}$ Del repàs de les seves obres, però, en resulta l'evidència d'un dels intents més clars de penetració, en el seu moment, d'una ciència sociològica, ben allunyada de tot el que significava la doctrina social de l'Església catòlica.

\section{L'OBRA ESCRITA DE SANTIAGO VALENTI I CAMP}

Fortament inftüit pel seu pare, Valentí va adquirir una formació de rang universitari poc ortodoxa $\mathrm{i}$ sempre mantingué fortes connexions amb

12. E. Navarro, Historiq critica... Prologo de Pere Corominas. Resamenes bistóricos de Emiliano Iglesias y Juan Arderius, Barcelona, 1915.

13. Jerez Mir a l'obra cit., p. 49 indica que Valentí i Camp fou deixeble de la darrera etapa madrilenya de Sales i Ferré. Cap altra dada ha pogut ser trobada per corroborar-ho. Es més, Valentí mateix, el 1908, a Ia seva obra Atisbos y disquisiciones reconeix com a únic mestre de tendència krausista Francisco Ginet de los Róos. 
el món cultural estranger en general i madrileny en particular. Segons ell mateix explicà, ${ }^{14}$ sense accedir mai a un curriculum regulat acadèmicament, va seguir de prop el moviment de la produccí sociològica a Anglaterra, Estats Units, Bèlgica, Alemanya molt especialment, Ftança, Itàlia, Països Baixos i Escandinaus. Sembla que aquesta recerca de coneixement a l'estranger va estar motivada per la precarietat que la formació acadèmica espanyola del moment li oferia. D'aquesta oferta, segons la seva opinió, únicament podia salvar-se Leopoldo Alas "Clarín» a la Universitat d'Oviedo, Valentí Vivó i els seus cursos de Medicina Legal i Toxicologia a Barcelona, i la càtedra de Filosofia del Dret de Giner de los Ríos a Madrid, on el jove sociòleg confessà haver fet l'aprenentatge de l'obra de Spencer, Schäffle, Worms, Novicow, Simmel i Ward entre altres.

El seu primer llibre es va publicar a Madrid, el 1899, amb un pròleg del jurista Alfredo Calderón, un dels seus més fidels collaboradors, i portava per títol Bosquejos sociológicos. El 1907 publicà, amb ptòleg d'Adolfo Bonilla, Premoniciones y reminiscencias, a la collecció «Biblioteca Sociológica Internacional», que ell mateix dirigia a Barcelona. En aquesta collecció es van arribar a publicar gairebé un centenar d'obres d'entre les més importants de la cultura sociològica internacional del moment. El 1908 s'edita Atisbos y Disquisiciones i també Lo antropología criminal y las disciplinas afines, text que recollia la ponència que va presentar al Congrés d'Antropologia Criminal, celebrat a Torí el 1906, al qual assistí com a regidor de I'Ajuntament de Barcelona. EI 1910 publicà La Democracia Socialista Alemana $y$ su organización $\mathrm{i}$, dos anys més tard, va escriute una obra en tres volums sobre Las sectas y las sociedades secretas a través de la bistoria en collaboració amb Enrique Massaguer.

Sense cap dubte, però, Vicisitudes y anbelos del pueblo español, escrita el 1908 i publicada tres anys després amb un pròleg del famós penalista Pedro Dorado Montero, és l'obra que presenta un interès sociològic més gran. En aquest cas, l'obra s'edità dins la collecció «Biblioteca Moderna de Ciencias Sociales» que també dirigia des de Barcelona, en collaboració amb el ja citat Alfredo Calderón. A Vicisitudes..., Valentí pretén fer un estudi de les característiques psico-sociològiques $\mathrm{i}$ antropològiques del poble espanyol. I de fet el llibre conté un petit manual del que al seu criteri ha de ser la sociologia científica, a més d'una valoració de l'estat d'aquesta ciència $i$ els seus professionals a l'España del moment.

A les pàgines prèvies al pròleg de Dorado Montero, l'autor fa la presentació de l'esmentada collecció, tot justificant-la per la necessitat d'impulsar el coneixement "positiu» d'una sociologia que faci front als dogmes i als

14. Proleg del seu llibre Atisbos y disquisiciones, Barcelona, 1908, p. VIII. 
irracionalismes. Les seves paraules són: «Hállase aún la Sociología en vías de formación (...). Un siglo de agitaciones (...). iCuántas faltas, cuántos errores, cuántas catástrotes se babrian evitado con sólo atender a los bechos $»^{15}$ I en la mateixa línia positivista continua dient: «Este sentido positivo constituye la característica de la Sociología novisima. Sobre la base firme de estadísticas serias, que ofrecen a la inducción el material indis. pensable, comienzan a esbozarse las ciencias de la Sociedad (...). Apunta la aurora del dia en que la sociedad bumana podrá ser regida por principios y no por dogmas, substituyendo la verdad científica a prejuicios tunestos y supersticiones nefandas.» ${ }^{16}$ Esperança «positivista» que Valentí veia refermar-se en la creació de diverses institucions dedicades cada cop més a l'estudi teóric i pràctic de la sociologia. Concretament de l'estranger citava la Nova Universitat de Brusselles, el Collegi Lliure de Ciències Socials de França, i d'Espanya feia esment de la Institución Libre de Enseñanza de Madrid i de l'Institut Social de Batcelona. ${ }^{17}$

Un cop d'ull al sumati del llibre desvet:lla a més l'afany de Valentí i Camp per aplicar els coneixements propis de la sociologia, ciència que ell considera emancipadora, a solucionar els problemes que la societat del moment pateix. Així, cal veure com després d'un capítol on explica breument els continguts de la teoria $\mathrm{i}$ el mètode sociologic, intenta descriure les principals característiques de Ia psicologia del poble espanyol, tot seguint els criteris de Le Bon. Quatre són, al seu parer, els factors que expliquen la gènesi de la manera de fer dels espanyols: el medi geogràfic, el medi psíquic i la influència de l'herència i la selecció. Però l'estudi no s'acaba aquí, la tesi del llibre es fa palesa en el capítol dedicat a delimitar els problemes de la «regeneració espanyola». La crítica arriba a qüestionar el sistema d'educació, la cultura, les arts i el grup social que segons l'autor té una major tesponsabilitat davant la crisi que la societat espanyola pateix: els intellectuals i per damunt de tots els sociolegs.

És així com Valentí fa esment com a exemple de culpables d'Eduardo Pérez Pujol, Concepción Arenal, Francisco Giner, Manuel Sales i Ferré, Gumersindo de Azcárate, Adolfo Posada, Buylla, Salillas, Sanz Escartín, Bernaldo de Quírós, grup de sociòlegs de l'època del qual exclon Dorado Montero i Valentí Vivó. Figures que al seu parer són les úniques que tenen "audacia y continuidad en el esfuerzo», mentre que la resta són acusats de tocar moltes disciplines sense cap aprofundiment, de no tenir poder crea-

15. Vicisitudes..., Barcelona, 1911, p. 2.

16. Vicisitudes..., p. 2.

17. L'Institut Social de Barcelona es va fundar el 1906 i va ser l'embrió del futur Museu Social (1910), entitat pionera en el desenvolupament d'una certa vessant de la sociologia catalana i de la qual Valentí i Camp formà part des dels inicis. 
dor i d'estar únicament interessats a destacar a les tertúlies. Aquestes actuacions són els motius pels quals ni l'Economia, ni la Psiquiatria, ni la Filosofia, ni la Sociologia, ni l'Antropologia, ni altres coneixements sobre qüestions socials són prou coneguts. Factors tots ells que units a la poca afecció a la lectura mantinguda en general pel poble espanyol constitueixen la font principal de tots els mals que el poble pateix. D'aquest diagnòstic Valentí en deriva que tots aquests mals no són atribuïbles, però, a problemes de taça sinó que són matèria de «psicologia colectiva y educación civica».

Un esperit similat es deriva del text publicat el 1922, Ideblogos, teorizantes $y$ videntes, que conté breus estudis sobre els autors que a criteri de Valentí marcaren una fita històrica a la filosofia i les ciències del segle XIX. Entre altres, A. Fouillée, W. James, R. Ardigó, M. Nordau, Spencer, Le Bon, Tarde, Durkheim, Sanz del Río, Dorado Montero, Huxley, Haeckel, Clatín, Costa, Ganivet, Schopenhauer, Betgson, Maeztu, Torras i Bages, Giner de los Ríos $\mathrm{i}$ altres membres del cortent krausista a Espanya. L'intetès primordial se centra, en aquest cas, en l'opinió que li mereixen els membres fundadors de la Institución Libre de Enseñanza i també els principals sociòlegs del moment. Sobre els primers, cal dir que el seu habitual pessimisme es capgira en lloances. Pel que fa als segons, cal destacar els retrets dirigits a Spencer davant la incomprensió que aquest sociòleg anglès mostrà vers el socialisme com a solució dels problemes que la societat de l'època tenia plantejats. Tatde fou mereixedor de millors elogis però van ser Le Bon $i$ especialment Durkheim els autors als quals demostrà la seva més fervent admiració. D'aquest darter n'admirà l'oberta disposició vers els seus deixebles i el fet d'haver estat el creador de l'escola francesa de sociologia. Per últim, com a detall anecdòtic d'aquest «santoral», cal destacar els elogis que Valentí dedicà a la figura de Torras i Bages, tot i que els plantejaments ideològics i sociològics del bisbe català li quedaven ben tluny.

\section{SANTIAGO VALENTI I CAMP I L'EMANCIPACIO FEMENINA}

Una altra característica de la poc ortodoxa figura de l'autor en qüiestió és el seu interès pels temes relatius a l'emancipació de la dona. En el seu llibre Vicisitudes $y$ anbelos... es va mostrar fervent defensor d'un paper més actiu per a la dona en la societat, tot valorant la influència que en aquest afer té l'educació pel futur de les persones. Aquestes idees tenien al seu parer una base científica, tal com - segons ell-w ja havia demostrat la doctora en Medicina Magdalena Pelletier. Aquesta doctora en un estudi 
publicat a la Revue Socialiste demostrava com Ia dona no era ni fisiolò gicament ni psicològicament inferior a l'home..$^{18} \mathrm{En}$ aquest mateix sentit, cal remarcar també com en el text que ara es comenta, a l'hora de destacar quins exen els nous moviments socials sorgits a la societat espanyola de l'època, Valentí citava explícitament el sindicalisme i el feminisme, com els més importants.

Aquestes no van ser les úniques referències escrites relatives al tema. En la seva prolífica carrera com a assagista publicà, segons expliquen els seus biografs, Las reivindicaciones femeninas, el 1913, amb ptòleg de Regina Lamo de Espinosa $i$ un apèndix de 3.150 obres relatives al problena femení. Dos anys abans de la seva mort, succeìda el 1934 quan tenia 59 anys, va escriure La mujer ante el amor y frente a la vida $\mathrm{i}$ un any després publicà Elena Key: Libertod de amar y la mujer de mañana i Eva redimida $y$ redentora. Obres totes elles que més enIlà de l'interès concret del text escrit palesen en certa manera la coherència d'un sociòleg en el moment d'analitzar la societat que l'envolta.

Amb tot el que s'ha dit firs ara, sembla evident que el paper de pioner de la sociologia i de les reivindicacions feministes li escau d'allò més bé a Santiago Valentí i Camp. Per sorprenent que pugui semblar, es podria fins i tot aventurar la idea que l'agermanament d'ambdues matèries no va ser un afer gens estrany entre els pioners de la sociologia espanyola. Adolfo Posada, prou teconegut per tothom com un dels pares d'aquesta ciència, va ser també un dels primers homes defensors de l'emancipació de la dona a Espanya. ${ }^{19}$.

Sobre l'evolució posterior soferta pels estudis sociològics i pel feministhe com a matèria d'estudi tractats bé separadament, bé conjuntament, pels sociolegs hereus d'aquests pioners no és aquest el moment de fer-ne valotacions, encara que a cop d'ull se saben molt distintes. D'altra banda, i en aquesta mateixa perspectiva, repassar la literatura produïda aquests darrers anys a l'entorn dels moviments socials també pot donar sorpreses com la de retrobar-hi com a nou moviment, al costat de l'ecologisme, el pacifisme, etc., el ferninisme, que a primers de segle ja tenia caràcter de novetat. I per últim, si s'examina amb detall la nòmina dels sociòlegs que, dins l'àmbit català en particular i espanyol en general, inclouen dins dels seus objectes d'estudi la problemàtica femenina a l'hora de parlar de les desigualtats so-

18. Vicisitudes..., p. 268.

19. Vegeu per exemple els articles que Posada va publicat a La Revista Socialista (LRV): *La mujer y las preocupaciones sociales» (LRV), núm. 9, Madrid, 1903 y «El sugragio femenino» (LRV), núm. 30, Madrid, 1904. Com també el que diu al respecte Amalia Mattín Gamero, néta de Posada, a Antología del feminismo, Madrid, 1975. 
cials, es podrà comprovar fàcilment que, en aquest cas, la variable sexe sí discrimina i no precisament en sentit positiu.

Però totes aquestes qüestions potser caldrà deixar-les per una altra ocasió perquè semblen escapar del tema dels orígens de la sociologia catalana. Com a punt final, només afegir que qualsevol estudiant de Metodologia coneix la complexitat que envolta la construcció dels objectes d'estudi al camp de les ciències socials. I que aquesta qüestió ha estat, és i serà motiu de grans $\mathrm{i}$ interessants controvèrsies. Aquests breus apunts històrics sobre els interessos d'un pioner poc conegut a la sociologia catalana no pretenen anar més enllà. En tot cas i per acabar recordar tan sols que el tema de les desigualtats per motiu de sexe en general i del femení en particular, formen part dels molts tòpics que l'anălisi de la tealitat social poques vegades desvetlla. 